Artur Zbiciak

Prof. dr hab. inż.

Wydział Inżynierii Lądowej

Politechnika Warszawska

A.Zbiciak@il.pw.edu.pl

Kazimierz Józefiak

mgr inż. , asystent

Wydział Inżynierii Lądowej

Politechnika Warszawska

k.jozefiak@il.pw.edu.pl

Radosław Czubacki

dr inż., adiunkt

Wydział Inżynierii Lądowej

Politechnika Warszawska

r.czubacki@il.pw.edu.pl

Patrycja Chacińska

mgr inż.

Instytut Ochrony Środowiska

Państwowego Instytutu Badań

Warszawa

DOI: 10.35117/A_ENG_21_09_03

\title{
FEM simulations of acoustic wave propagation in the vicinity of the railroad structure
}

Keywords: Finite Element Method; Acoustics; Railway Noise

\begin{abstract}
Noise is one of the major environmental concerns nowadays. The problem is especially significant around large urban agglomerations where high levels of noise can have a negative impact on physical or psychological well-being of citizens while a long-term exposure can be harmful to health. Residential areas are protected by the introduction of maximum allowable sound pressure levels according to appropriate norms. There are also similar regulations concerning natural areas under environmental protection. Different measures used in order to reduce levels of noise should be applied primarily to the source of the sound. This is the task mainly for the manufacturers of all kinds of machines as well as means of transport. However, noise levels can be also controlled by the introduction of appropriately designed or chosen elements or materials in civil engineering structures. The noise levels emitted by the rail traffic depend on the number, kind and speed of trains, night and day traffic organization as well as on the type of the railroad structure and its location (e.g. on an embankment, on a bridge or flyover). Railway noise mainly develops between wheels and rails and depends on the roughness of both these elements, rolling speed and dynamic characteristics of the railroad. The paper presents the mathematical formulation of a coupled acoustic-structure problem. Solving the problem with finite element method gives the possibility to predict sound pressure levels in the vicinity of a railway structure. A numerical model of a certain type of a railroad structure was built in order to simulate the acoustic wave propagation caused by a wheel-rail interaction. The harmonic analysis was carried out using the Abaqus software. The acoustic pressure
\end{abstract}


obtained based on the harmonic analysis was evaluated in certain points of the acoustic medium for various excitation frequencies. The final results were presented in the form of one-third octave bands. In the article, a possible methodology for estimating noise levels from railway structures based on a numerical analysis was shown. In the future works, the numerical model will be validated by field test data and applied to evaluate different types of technological solutions (silencers) used to reduce railway noise levels.

This paper is part of the project "Innovative solutions for the protection of people and building against noise from rail traffic". The project is co-financed by the European Union from the European Regional Development Fund within the framework of the Smart Growth Operational Programme and by PKP PLK S.A. within the framework of a joint venture BRIK.

\section{Introduction}

Noise is one of the basic environmental problems [11]. One of the main sources of traffic noise is the one from railway lines (in addition to road and aircraft noise). Due to its harmfulness, permissible noise levels have been defined. They vary depending on the source of the noise and the reference time (e.g. daytime, night) as well as the type of destination of the area where it is determined.

Due to the nature of the noise phenomenon, protective measures should primarily consist in limiting its source. It is a task for manufacturers of machines, devices, and means of transport and structural designers who apply for appropriate acoustic protection in construction and engineering facilities. In the case of railways, the level of sound emission depends on the number, type and speed of trains, the type, the technical condition of the track and its course (e.g. on an embankment, in a trench, on a viaduct or a bridge, densely built-up areas) [9]. Railway noise mainly arises at the interface between wheel and rail; depends on the roughness of both these elements, the rolling speed and the dynamic characteristics of the track.

Currently, many commercial finite element method (FEM) programs allow modeling and simulation analysis of physical fields and coupled phenomena. General purpose MES programs such as Abaqus, Ansys, Comsol et al. enable the analysis of steady-state and transient issues in the field of solid state mechanics, fluid mechanics, acoustics, thermodynamics and electromagnetism. Many of the above-mentioned programs contain tools that facilitate the simulation study of "multiphysics" phenomena, in the form of libraries of special finite elements, procedures for solving systems of differential equations, specific for a given problem, or additional tools in the field of post-processing. In many programs, such tools are concentrated in separate modules (e.g. in Comsol: Acoustics Module, CFD Module, AC / DC Module and many others).

The subject of this study is the presentation of the FEM simulation model used to analyze the phenomenon of acoustic wave propagation in the vicinity of the rail surface structure. In this problem, there is a coupling of two physical fields (domains): (i) a solid, which is the structure of the rail surface, and (ii) a fluid (the air surrounding the structure of the rail surface). In the domain of a solid, we are looking for the fields of displacements, strains and stresses at each point of the structure, while in the area of a fluid, we are looking for velocity and acoustic pressure fields. The model of the problem under consideration was built in the Abaqus program; the results of computer calculations were presented with the use of additional programming tools of the authors.

\section{Sound pressure}

Acoustic vibrations of air particles cause cyclical thickening and dilution of the medium, thus causing temporary differences between the pressure existing at a given point at the moment of the passage of the acoustic wave and the static atmospheric pressure. We call these differences the sound pressure [10]. Changes in acoustic pressure are a stimulus that produces sound 
sensations. The range of changes in the sound pressure recorded by the hearing organ is within the limits from $20 \mu \mathrm{Pa}$ to $20 \cdot 10^{7} \mu \mathrm{Pa}$. Due to the very large range of the acoustic pressure values and the fact that our perception is influenced not by the arithmetic difference between the compared stimulus sizes, but by the ratio of the compared quantities (the so-called WeberFechner law $[5,10])$, the level of the sound pressure is presented on a logarithmic scale according to the relationship:

$$
L_{p}(p)=20 \log _{10}\left(\frac{p_{r m s}}{p_{r e f}}\right) \mathrm{dB}
$$

where: $p_{\text {ref }}=20 \mu \mathrm{Pa}$ - reference pressure value, $p_{r m s}[\mathrm{~Pa}]$ - root-mean-square pressure.

The next part of the paper presents the formulation of the coupled mechanical-acoustic problem, the solution of which - with the use of FEM - allows for simulation determination of the acoustic pressure level at any point in the surroundings of the rail surface structure.

\section{Mathematical formulation}

\section{The equations for elasticity of continuous media}

Continuous medium equations are formulated in Lagrange's (material) description. Assuming small displacements and low velocities, the equations of motion in the area in the case of a continuous medium (the law of conservation of momentum) simplify to the form [7, 15]:

$$
\rho \frac{\partial^{2} u_{i}}{\partial t^{2}}=\frac{\partial \sigma_{i j}}{\partial x_{j}}+\rho g_{i}+f_{i}
$$

where Einstein's summation convention applies. In the equation (2) $\sigma_{i j}$ are the components of the stress tensor $\boldsymbol{\sigma}, u_{i}$ the components of the particle displacement vector $\mathbf{u}, \rho$ the material density, $g_{i}$ the components of the gravitational acceleration vector $\mathbf{g}$. The components $f_{i}$ represent additional external mass forces, the occurrence of which is due to coupling with another physical model. The components of the displacement vector of a molecule $u_{i}$ are functions of time and position. Equation (2) should be supplemented with initial conditions and the following boundary conditions:

$$
\begin{array}{ll}
u_{i}=\bar{u}_{i} & \text { na } \Gamma_{u}^{t} \\
\sigma_{i j} n_{j}=h_{i} & \text { na } \Gamma_{h}^{t}
\end{array}
$$

where $h_{i}$ are components of the surface force vector, which can also result from the interaction of fluids or electrostatic and magnetic fields.

The body movement must also satisfy the continuity equation (the law of conservation of mass):

$$
\frac{\partial \rho}{\partial t}+\frac{\partial\left(\rho v_{i}\right)}{\partial x_{i}}=0
$$

where $v_{i}$ are the components of the particle velocity vector $\mathbf{v}$. The constitutive equations of a linear anisotropic medium can be written as:

$$
\sigma_{i j}=C_{i j k l} \varepsilon_{k l}
$$

where $C_{i j k l}$ are components of the material constant tensor $\mathbf{C}$ (4th order tensor), $\varepsilon_{k l}$ are components of a strain tensor (2nd order tensor). In the case of an isotropic linear elastic material, the compound (5) is reduced to the form: 


$$
\sigma_{i j}=\frac{E v}{(1+v)(1-2 v)} \varepsilon_{k k} \delta_{i j}+\frac{E}{(1+v)}
$$

where material constants $E$ and $v$ are called Young's modulus and Poisson's ratio, respectively. Assuming small displacements, the components of the state of deformation are calculated from the formula:

$$
\varepsilon_{i j}=\frac{1}{2}\left(\frac{\partial u_{i}}{\partial x_{j}}+\frac{\partial u_{j}}{\partial x_{i}}\right)
$$

\section{Acoustics equations}

The equations of fluid mechanics are formulated in Euler's (spatial) description. The laws of conservation of mass, momentum and energy in an area $\Omega_{t}^{f}$ can be expressed as follows [1, 13, 15]:

$$
\begin{gathered}
\frac{\partial \rho}{\partial t}+\frac{\partial\left(\rho v_{i}\right)}{\partial x_{i}}=0 \\
\frac{\partial\left(\rho v_{i}\right)}{\partial t}+\frac{\partial\left(\rho v_{i} v_{j}\right)}{\partial x_{j}}=\frac{\partial \sigma_{i j}}{\partial x_{j}}+\rho g_{i}+f_{i} \\
\frac{\partial(\rho e)}{\partial t}+\frac{\partial\left(\rho v_{i} e\right)}{\partial x_{i}}=\mu \frac{\partial v_{i}}{\partial x_{j}} \sigma_{i j}+\frac{\partial}{\partial x_{i}}\left(\kappa_{f} \frac{\partial T}{\partial x_{i}}\right)+\rho q
\end{gathered}
$$

where $e$ is the internal energy per unit volume, $\mu$ as dynamic viscosity, $q$ external heat source, and $\kappa_{f}$ thermal conductivity coefficient.

The constitutive relationship of a compressible Newtonian fluid is as follows [13]:

$$
\sigma_{i j}=\mu\left(\frac{\partial v_{i}}{\partial x_{j}}+\frac{\partial v_{j}}{\partial x_{i}}-\frac{2}{3} \frac{\partial v_{k}}{\partial x_{k}} \delta_{i j}\right)-p \delta_{i j}
$$

With a non-viscous fluid ( $\mu=0$ ) equations (9) and (10) simplify to the form of Euler equations [13]:

$$
\begin{gathered}
\frac{\partial\left(\rho v_{i}\right)}{\partial t}+\frac{\partial\left(\rho v_{i} v_{j}\right)}{\partial x_{j}}=-\frac{\partial p}{\partial x_{i}}+\rho g_{i}+f_{i} \\
\frac{\partial(\rho e)}{\partial t}+\frac{\partial\left(\rho v_{i} e\right)}{\partial x_{i}}=-p \frac{\partial v_{i}}{\partial x_{i}}
\end{gathered}
$$

Acoustic equations are a special case of fluid mechanics equations. The basic assumptions for the acoustic medium are as follows [13, 15]:

- the center is compressible,

- the medium is not sticky (zero viscosity),

- there are no mass forces $\left(g_{i}=0, f_{i}=0\right)$,

- the medium is at rest (the average flow velocity is zero),

- the center is homogeneous,

- changes in fluid pressure and density are small,

- the medium is an ideal gas and the process is adiabatic.

Assuming the above assumptions, the continuity equation (8) can be written as follows:

$$
\frac{\partial \rho}{\partial t}+\rho_{0} \frac{\partial v_{i}}{\partial x_{i}}=0
$$
the form:

The equilibrium equation (12) (the law of conservation of momentum) is simplified to 


$$
\rho_{0} \frac{\partial v_{i}}{\partial t}+\frac{\partial p}{\partial x_{i}}=0
$$

In the Abaqus program, an additional term related to the homogeneous, isotropic volumetric drag is introduced into the equilibrium equation, so that equation (15) takes the form [3]:

$$
\rho_{0} \frac{\partial v_{i}}{\partial t}+\frac{\partial p}{\partial x_{i}}+\gamma v_{i}-\rho g_{i}=0
$$

where $\gamma$ is the volumetric drag coefficient.

Acoustic phenomena are adiabatic processes where there is a non-linear relationship between the pressure and the density of the fluid (gas). Assuming that the changes in pressure and density are small, i.e. $\mathrm{d} p_{0} / \mathrm{d} \rho_{0}=p / \rho$, we receive relationship:

$$
p=K_{f} \frac{\rho}{\rho_{0}}
$$

where $K_{f}$ is the modulus of volumetric compressibility. After substituting the relation (17) to the continuity equation (the laws of conservation of mass), we obtain the constitutive relation of the acoustic medium:

$$
\frac{\partial p}{\partial t}+K_{f} \frac{\partial v_{i}}{\partial x_{i}}=0
$$

which leads to a relationship:

$$
p=-K_{f} \frac{\partial u_{i}}{\partial x_{i}}
$$

Equations (14) and (15) should be supplemented with appropriate boundary conditions [15]:

and the initial conditions:

$$
\begin{aligned}
& v_{i}=\bar{v}_{i} \quad \text { na } \Gamma_{u}^{f} \\
& \sigma_{i j} n_{j}=h_{i} \quad \text { na } \Gamma_{h}^{f}
\end{aligned}
$$

$$
\begin{array}{llll}
v_{i}(0)={ }^{0} v_{i} & \mathrm{w} & \Omega^{f} \\
p(0)={ }^{0} p & \mathrm{w} & \Omega^{f}
\end{array}
$$

\section{Mechanical-acoustic coupling}

The system of equilibrium equations of continuum mechanics of the finite element method can be written as follows [15]:

$$
\mathbf{M}_{e}^{s} \ddot{\mathbf{u}}{ }_{e}+\mathbf{C}_{e}^{s} \dot{\mathbf{u}}+\mathbf{K}_{e}^{s} \mathbf{u}_{e}=\mathbf{F}_{e}^{s}+\mathbf{F}_{e}^{p r}
$$

where $\mathbf{M}_{e}^{s}$ - finite element mass matrix of continuous medium, $\mathbf{C}_{e}^{s}$ - continuous medium element damping matrix, $\mathbf{K}_{e}^{s}$ - the stiffness matrix of an element of a continuous medium, $\mathbf{F}_{e}^{s}$ - vector of loads on an element of a continuous medium, $\mathbf{F}_{e}^{p r}$ - force vector of an element related to pressure from fluids on the interface surface $\Gamma_{0}$. The interface is understood as a common contact area between the solid domain and the fluid domain. Vector $\mathbf{F}_{e}^{p r}$ can be obtained by integrating the pressure across the interface [15]:

$$
\mathbf{F}_{e}^{p r}=\mathbf{R}_{e} \mathbf{p}_{e}
$$

where $\mathbf{p}_{e}$ - pressure vector, $\mathbf{R}_{e}-$ transformation matrix

$$
R_{e}=\int_{\Gamma_{0}} \mathbf{N}_{u} \mathbf{n}\left(\mathbf{N}_{p}\right)^{T} \mathrm{~d} \Gamma
$$


with components:

$$
\left[R_{e}\right]_{a i, b}=\int_{\Gamma_{0}} \mathbf{N}_{u}^{a} \mathbf{n}_{i} \mathbf{N}_{p}^{b} \mathrm{~d} \Gamma
$$

where $\mathbf{N}_{u}^{a}$ - the function of the shape of displacements in $a$ node and an element of a continuous medium, $\mathbf{n}_{i}$ - normal unit vector on the interface where compression takes place on the i-th element of the fluid (acoustic medium), $\mathbf{N}_{p}^{b}$-the function of the shape of the sound pressure in the $b$ node of the acoustic element. Substituting equation (23) to (22) we obtain:

$$
\mathbf{M}_{e}^{s} \ddot{\mathbf{u}}_{e}+\mathbf{C}_{e}^{s} \dot{\mathbf{u}}+\mathbf{K}_{e}^{s} \mathbf{u}_{e}-\mathbf{R}_{e} \mathbf{p}_{e}=\mathbf{F}_{e}^{s}
$$

The equation system of the finite element method of an acoustic medium can be represented as follows [15]:

$$
\mathbf{M}_{e}^{f} \ddot{\mathbf{p}}_{e}=\mathbf{C}_{e}^{f} \dot{\mathbf{p}}_{e}+\mathbf{K}_{e}^{f} \mathbf{p}_{e}+\rho_{0}\left(\mathbf{R}_{e}\right)^{T} \ddot{\mathbf{u}}_{e}=\mathbf{0}
$$

where $\mathbf{M}_{e}^{f}$ - finite element mass matrix of the acoustic medium, $\mathbf{C}_{e}^{f}-$ an acoustic medium element damping matrix, $\mathbf{K}_{e}^{f}-$ the stiffness matrix of the acoustic medium element, $\mathbf{R}_{e}-$ transformation matrix (24).

Using the equations (26) and (27), the system of equations of the conjugate acoustic problem can be formulated in the matrix form [15]:

$$
\left[\begin{array}{cc}
\mathbf{M}^{s} & \mathbf{0} \\
\mathbf{M}^{f s} & \mathbf{M}^{s}
\end{array}\right]\left\{\begin{array}{c}
\ddot{\mathbf{u}} \\
\ddot{\mathbf{p}}
\end{array}\right\}+\left[\begin{array}{cc}
\mathbf{C}^{s} & \mathbf{0} \\
\mathbf{0} & \mathbf{C}^{f}
\end{array}\right]\left\{\begin{array}{l}
\dot{\mathbf{u}} \\
\dot{\mathbf{p}}
\end{array}\right\}+\left[\begin{array}{cc}
\mathbf{K}^{s} & \mathbf{K}^{f s} \\
\mathbf{0} & \mathbf{K}^{f}
\end{array}\right]\left\{\begin{array}{l}
\mathbf{u} \\
\mathbf{p}
\end{array}\right\}=\left\{\begin{array}{c}
\mathbf{F}^{s} \\
\mathbf{0}
\end{array}\right\}
$$

where the mass matrix of the coupled acoustic-structural problem:

$$
\mathbf{M}^{f_{s}}=\sum_{e} \mathbf{M}_{e}^{f_{s}} \quad \mathbf{M}_{e}^{f_{s}}=\rho_{0} \mathbf{R}_{e}^{T}
$$

and the stiffness matrix of the coupled acoustic-structural problem:

$$
\mathbf{K}^{f_{s}}=\sum_{e} \mathbf{K}_{e}^{f_{s}} \quad \mathbf{K}_{e}^{f_{s}}=-\mathbf{R}_{e}
$$

Equations (28) can be solved directly with sound pressure and displacements updated simultaneously. This equation can also be solved, assume a weak form of coupling, in which the sound pressure is treated as a load on a continuous medium, and the displacements and accelerations constitute the excitation of the acoustic medium [15].

\section{FEM model description}

In order to estimate the propagation of the acoustic wave caused by the passage of the train wheel, a numerical model of the railway ballast pavement structure shown in Figure $\mathbf{1}$ was built. The problem was modeled in a plane deformation state. The MES Abaqus program was used in the calculations.

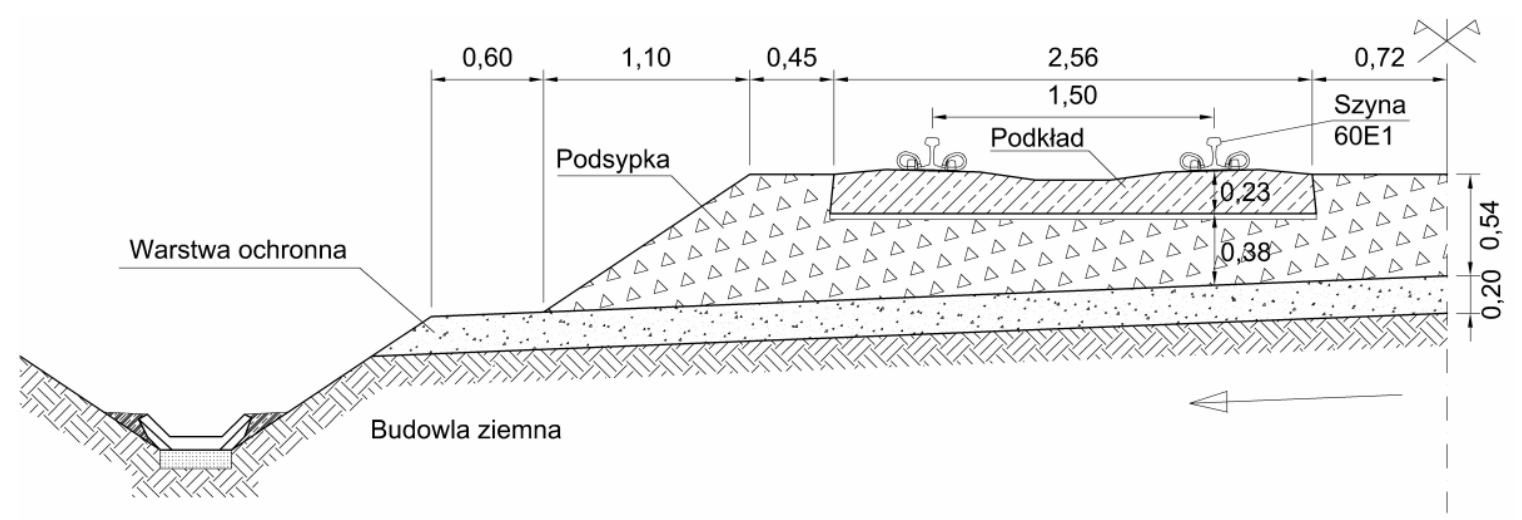

1. Railway structure accepted for FEM analysis dimensions in meters 
The geometry of the numerical model and the adopted boundary conditions are shown in Figure 2. Due to the fact that the damping in a continuous medium was not modeled, the coupling between the acoustic medium and the pavement structure was assumed only at the edge of the sleeper and rails (red in Figure 2). On the remaining part of the shore, the conditions of perfect acoustic wave reflection were assumed. Such conditions reflect the most unfavorable case (we obtain overestimated values of the sound pressure level), which may correspond, for example, to the situation of gravel icing. At the edge of the acoustic medium, conditions were assumed to absorb acoustic waves, which are an alternative to infinite acoustic finite elements. The FEM model was divided into 67,330 acoustic and structural finite elements. Eight-node acoustic elements with quadratic interpolation and construction elements in a flat state of fournode deformations with linear interpolation and reduced integration were assumed. Figure 3 shows a detail of the adopted FEM mesh in the area of rails and sleepers.

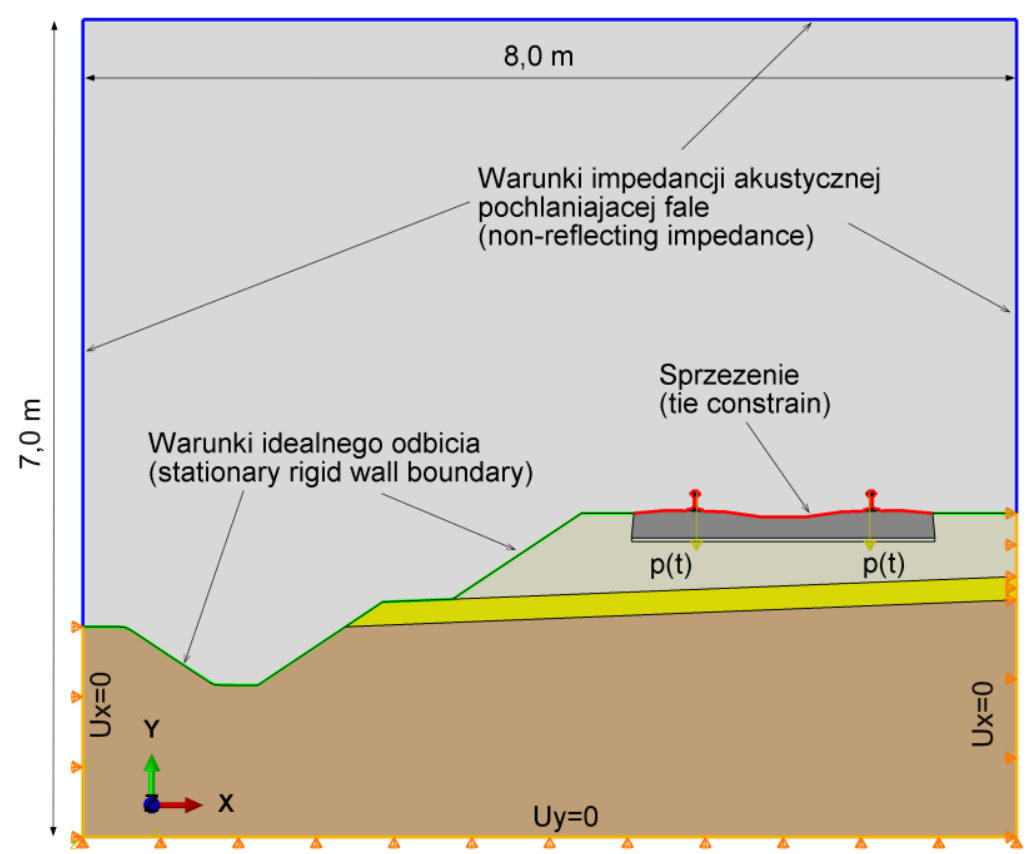

2. Dimensions, boundary conditions and loads in the FEM model

The adopted material parameters of the individual layers of the structure and the acoustic medium are shown in Table $\mathbf{1}$. In the case of structural elements, a linear-elastic material model was adopted.

The harmonic analysis in the frequency domain was performed. The load was assumed in the form of a pair of sinusoidally concentrated forces (harmonic analysis) $q(t)=A \sin \omega t$ where $\omega=2 \pi f$, with an amplitude equal to:

$$
A=\frac{22,5 \mathrm{t}}{2}=11250 \mathrm{~kg} \cdot 9,81 \frac{\mathrm{m}}{\mathrm{s}^{2}}=110,362 \mathrm{kN}
$$

as for wagons with a load of 22.5 t/axle according to [6]. The loads were applied to the railhead (see Figure 2) at points slightly shifted from the rail symmetry axis towards the center of the track. The frequency range of the excitation was tested from 17 to $3570 \mathrm{~Hz}$. 
Tab. 1. Assumed material parameters of individual elements of the FEM model

\begin{tabular}{|c|c|c|c|c|c|}
\hline \multirow{2}{*}{ Model element } & Material & Density & $\begin{array}{c}\text { Young's } \\
\text { modulus }\end{array}$ & Poisson's ratio & $\begin{array}{c}\text { Modulus of } \\
\text { volumetric } \\
\text { elasticity }\end{array}$ \\
\cline { 3 - 6 } & $\rho\left[\mathrm{kg} / \mathrm{m}^{3}\right]$ & $\mathrm{E}[\mathrm{MPa}]$ & $v[-]$ & $\mathrm{K}[\mathrm{MPa}]$ \\
\hline Air & Air & 1,247 & --- & --- & 0,100 \\
\hline Rail 60E1 & Steel & 7850 & 200000 & 0,30 & 166667 \\
\hline Rail support & Concrete & 2500 & 35000 & 0,23 & 21605 \\
\hline Ballast & $\begin{array}{c}\text { Crushed } \\
\text { stone }\end{array}$ & 2000 & 300 & 0,20 & 167 \\
\hline Protective layer & $\begin{array}{c}\text { Gravel } \\
\text { mix }\end{array}$ & 2000 & 150 & 0,20 & 83 \\
\hline $\begin{array}{c}\text { Ground } \\
\text { construction }\end{array}$ & $\begin{array}{c}\text { Cohesive } \\
\text { soil }\end{array}$ & 2000 & 35 & 0,30 & 29 \\
\hline
\end{tabular}

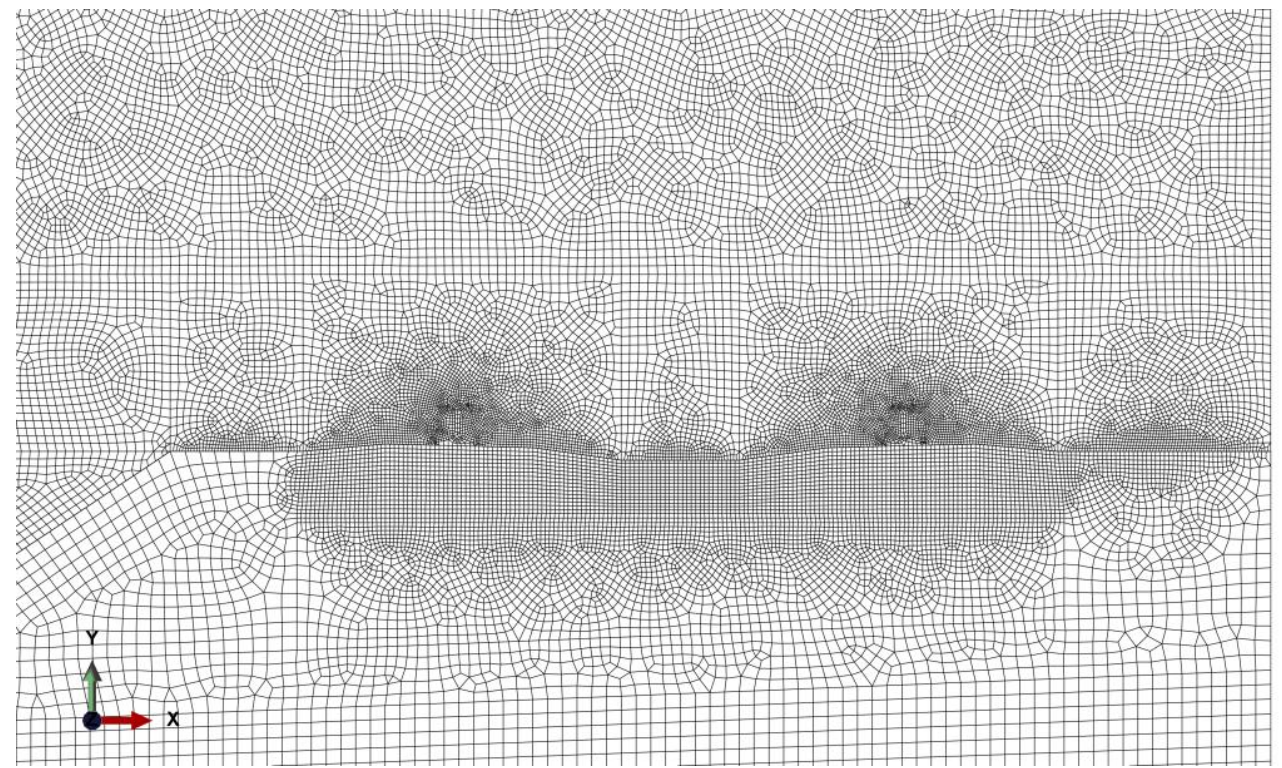

3. FEM mesh in the area of rails

\section{Results of numerical calculations}

The dependence of the acoustic pressure amplitude at selected points in the model on the excitation frequency was investigated. The locations of points A, B, C and D are shown in the figure 4.

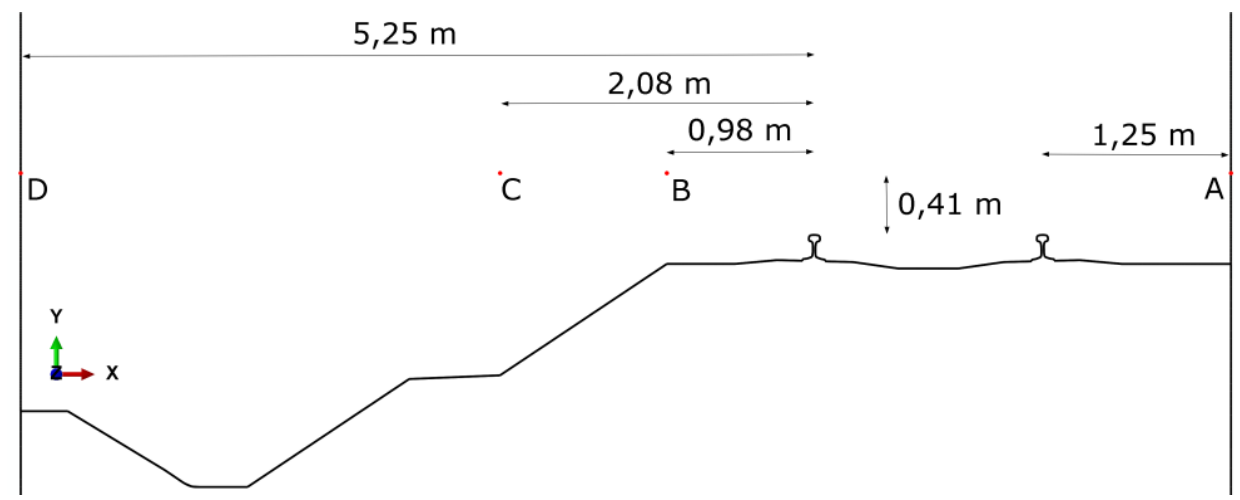

4. Location of the points from which the sound pressure values were read 
Figure 5 shows the values of the sound pressure level $L_{p}$ at point $\mathrm{C}$ for the analyzed excitation range from 17 to $3570 \mathrm{~Hz}$. Figure 6 summarizes the values of sound pressure levels at points $\mathrm{A}, \mathrm{B}, \mathrm{C}$ and $\mathrm{D}$ in $1 / 3$ octave bands.

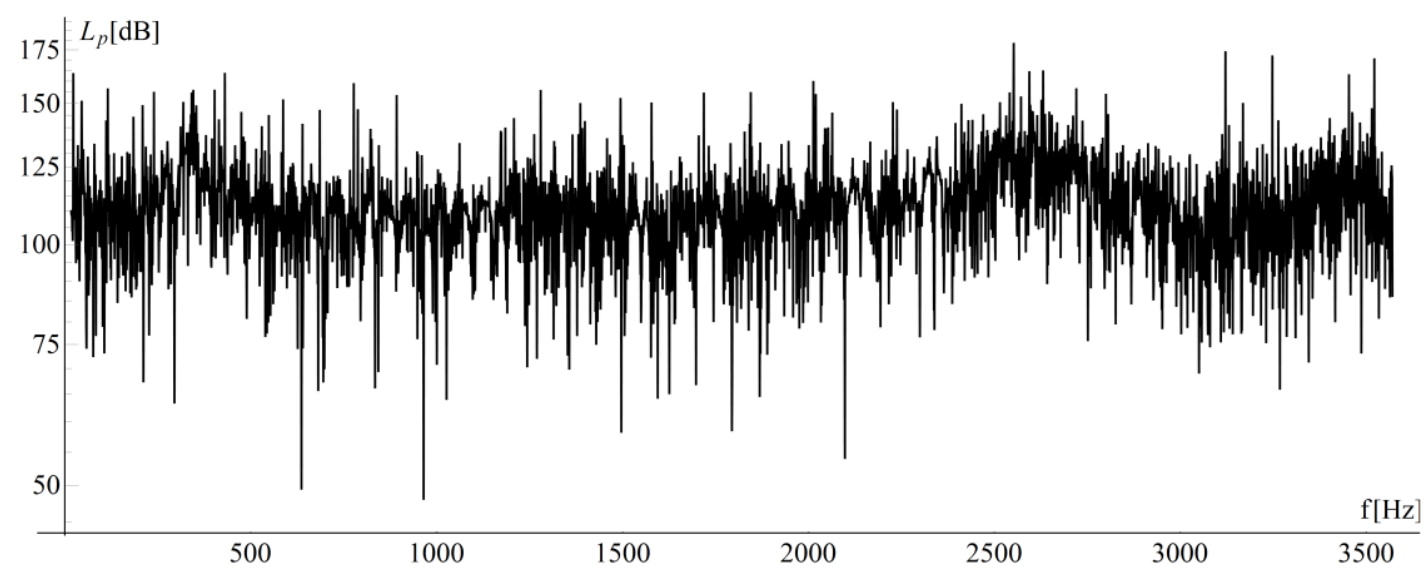

5. The sound pressure level at the measuring point $C$ depending on the excitation frequency

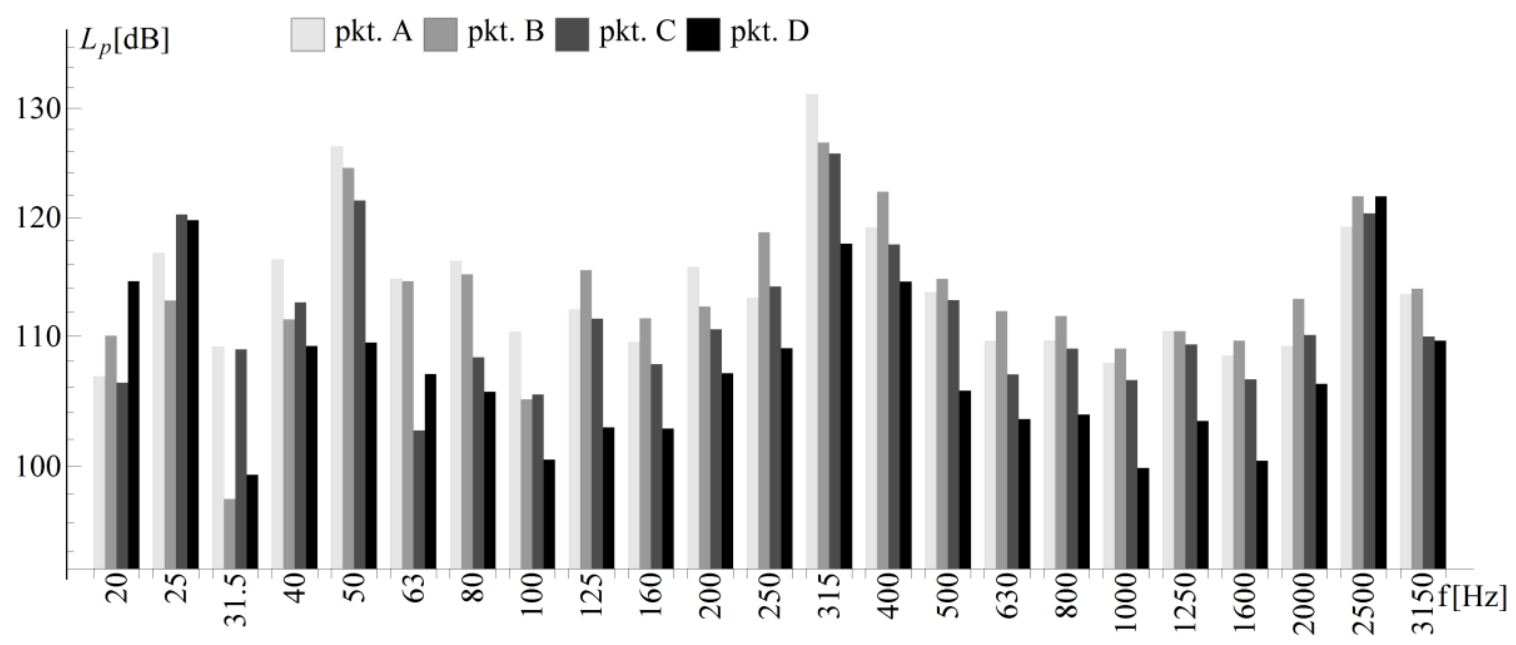

6. Sound pressure levels at points A, B, C and D in $1 / 3$ octave bands

Figure 7 shows an example of a contour map of the steady state sound pressure (Pa) at the excitation frequency of $816 \mathrm{~Hz}$. 


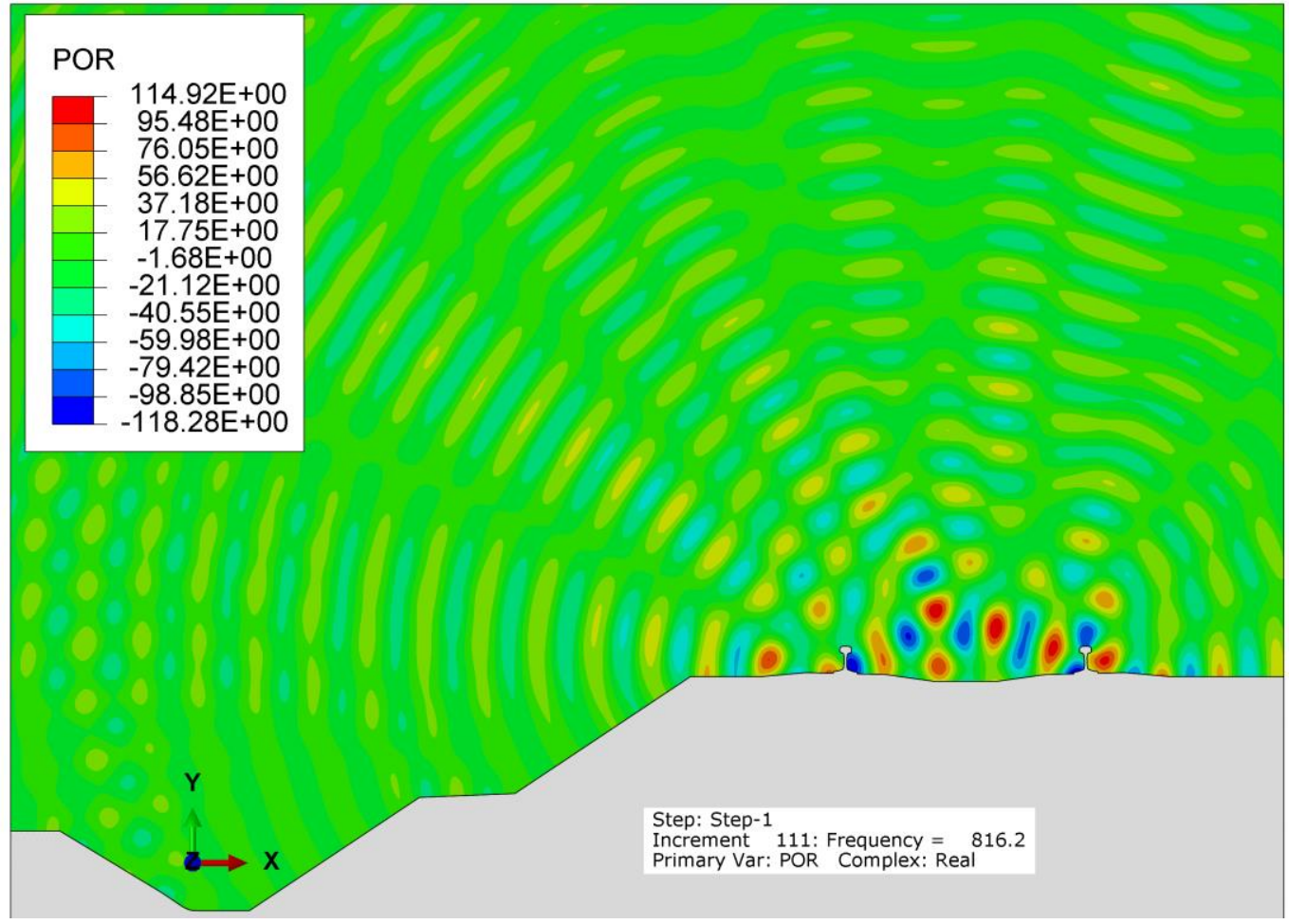

7. Contour plot of the steady state sound pressure $[\mathrm{Pa}]$ at the excitation frequency of $816.2 \mathrm{~Hz}$

\section{Summary}

Almost 10 million inhabitants of European agglomerations (cities with more than 100,000 inhabitants) are at risk from railway noise with an LDWN value $\geq 55 \mathrm{~dB}$ [14]. This problem also affects residents living along railway lines outside agglomerations. The scale of the phenomenon means that solutions that could reduce the nuisance of railway lines are still being sought.

One such way to combat noise is to define maximum levels of noise for new (conventional) railway vehicles. However, this solution does not apply to the rolling stock already in use. Hence the need to look for new technological solutions aimed at reducing railway noise with the use of innovative solutions in the form of track silencers and rail-side silencers [2].

In Poland, the Dutch method according to the study [12] of 1996, hereinafter referred to as RMR [8] and the CNOSSOS-EU method, which should apply from 31 December 2018 in accordance with the provisions of the directive [4], is currently in force. The commercial software used so far with the methods used (RMR, CNOSSOS-EU), there are no detailed libraries of these solutions that can be used directly to assess environmental noise. At present, only modifications are most often used, taking into account the roughness of the rail, the type of washers (soft, medium, hard), and the type of sleepers.

The methodology of rail traffic noise assessment discussed in the article on the basis of FEM numerical analysis carried out in the Abaqus program is an attempt to more accurately describe the phenomenon of changes in noise emissions from the railway line after the use of innovative solutions. The prepared model will be verified in further works on the basis of noise measurements and - after possible modifications - used to evaluate the adopted technological solutions. The problem identified in this way can then be implemented into the already existing methodologies for the assessment of noise emissions in the environment. 


\section{Acknowledgments}

The publication was created as part of the project "Innovative solutions for the protection of people and the environment against noise from rail traffic". The project is co-financed by the European Union from the European Regional Development Fund under the Intelligent Development Operational Program and by PKP PLK S.A. as part of the BRIK Joint Undertaking.

Fundusze Europejskie

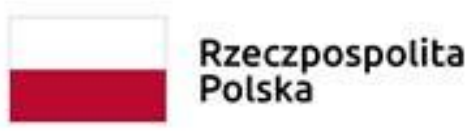

\section{Unia Europejska \\ Europejskie Fundusze Strukturalne i Inwestycyjne}

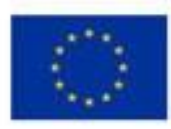

\section{Source materials}

[1] Bukowski J., Mechanika płynów, PWN, Warszawa, 1959

[2] Brzeziński K., Kraśkiewicz C. i in., Tłumiki torowe i przyszynowe jako innowacyjne rozwiązania dla ochrony ludzi i środowiska przed hałasem od ruchu kolejowego, Zeszyty Naukowo-Techniczne SITK RP Oddział w Krakowie, 2018, 1, 33-46

[3] Dassault Systèmes, Abaqus Analysis User's Manual Ver. 6.16, Dassault Systèmes, 2016

[4] Dyrektywa Komisji UE 2015/996 z dnia 19 maja 2015 r. ustanawiająca wspólne metody oceny hałasu zgodnie z dyrektywą 2002/49/WE Parlamentu Europejskiego i Rady

[5] Engel Z., Ochrona środowiska przed drganiami i hałasem, Wydawnictwo Naukowe PWN, Warszawa 1993

[6] PN-EN 15528: 2015-12, Kolejnictwo - Klasyfikacja linii w odniesieniu do oddziaływań pomiędzy obciążeniami granicznymi pojazdów szynowych a infrastrukturą, 2015

[7] Fung Y. C. Podstawy mechaniki ciała stałego, Państwowe Wydawnictwo Naukowe, 1965

[8] Kucharski R. i in. Wytyczne do sporządzania map akustycznych, GIOŚ, IOŚ-PIB, Warszawa, 2016

[9] Lipowczan A., Podstawy pomiarów hałasu, Główny Instytut Górnictwa i Liga Walki z Hałasem, Warszawa-Katowice, 1987

[10] Makarewicz R. Dźwięki i fale, Wydawnictwo Naukowe UAM, Poznań, 2017.

[11] Nurzyński J. Akustyka w budownictwie, Wydawnictwo Naukowe PWN, Warszawa, 2018

[12] Reken - en Meetvoorschrift Railverkeerslawaai '96, Ministerie Volkshuisvesting, Ruimtelijke Ordening en Milieubeheer, 20.11.1996

[13] Souli M., Benson D. J. (Ed.), Arbitrary Lagrangian-Eulerian and Fluid-Structure Interaction, WILEY, 2010

[14] www.eea.europa.eu/airs/2018/environment-and-health/environmental-noise, 2019

[15] Zhang Q., Song C. Multiphysics Modeling. Numerical Methods and Engineering Applications, Elsevier, 2016 